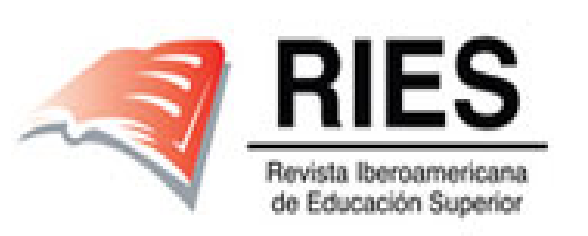

Revista Iberoamericana de Educación Superior

E-ISSN: 2007-2872

emmaro@unam.mx

Instituto de Investigaciones sobre la

Universidad y la Educación

México

de Vries, Wietse; Navarro, Yadira

¿Profesionistas del futuro o futuros taxistas? Los egresados universitarios y el mercado laboral en

México

Revista Iberoamericana de Educación Superior, vol. II, núm. 4, 2011, pp. 3-27

Instituto de Investigaciones sobre la Universidad y la Educación

.jpg, México

Disponible en: http://www.redalyc.org/articulo.oa?id=299124247001

- Cómo citar el artículo

- Número completo

- Más información del artículo

- Página de la revista en redalyc.org

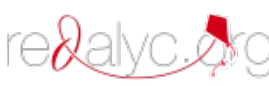

Sistema de Información Científica

Red de Revistas Científicas de América Latina, el Caribe, España y Portugal

Proyecto académico sin fines de lucro, desarrollado bajo la iniciativa de acceso abierto 


\section{Lerritorios}

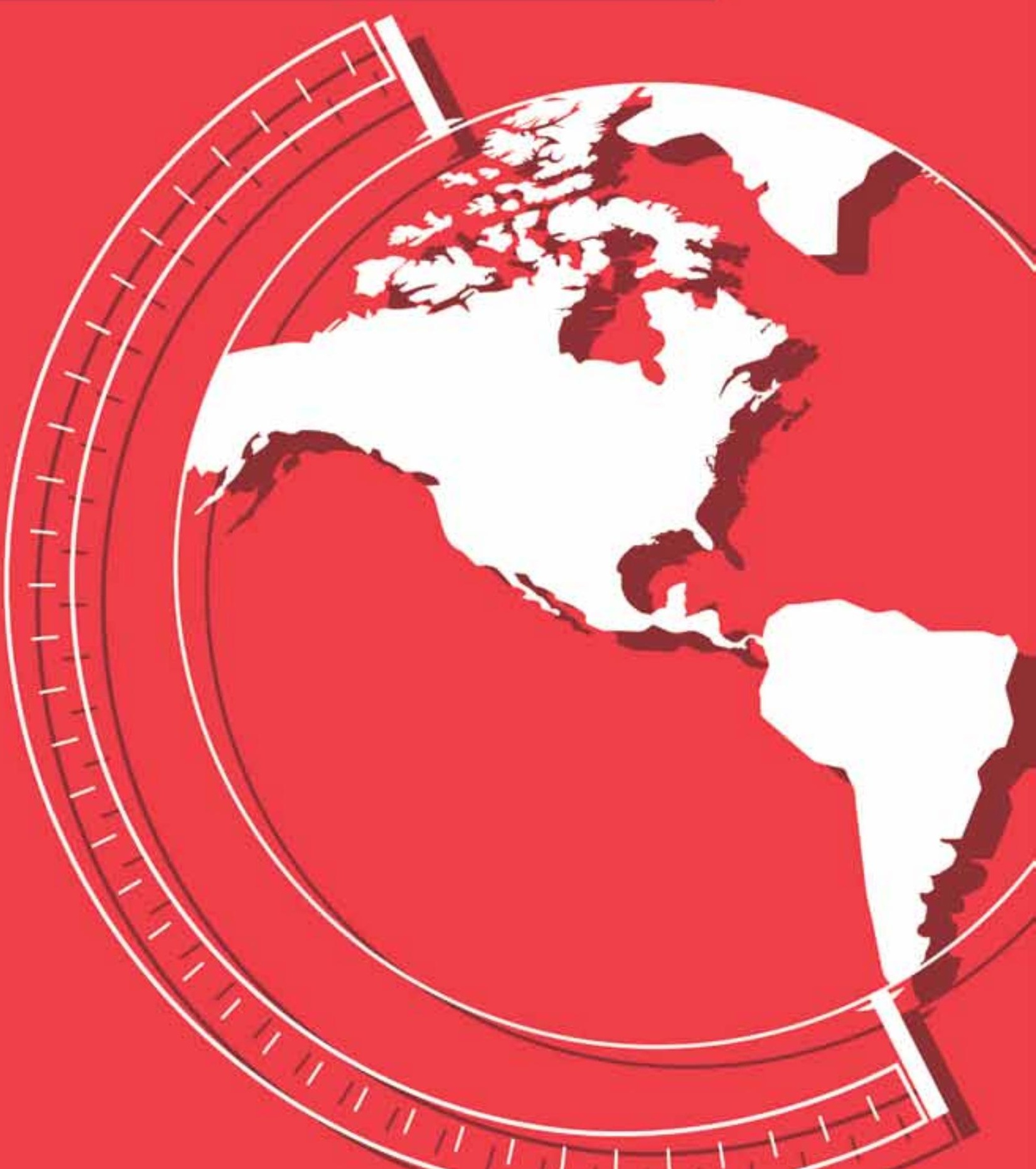




\title{
¿Profesionistas del futuro o futuros taxistas? Los egresados universitarios y el mercado laboral en México
}

Wietse de Vries y Yadira Navarro

\begin{abstract}
Resumen
El aporte que hace una universidad al futuro de sus estudiantes es un tema controversial. Informes oficiales acostumbran perfilar a la educación superior como el impulsor para el desarrollo económico y social, pero al mismo tiempo ponen esta aseveración en duda, al señalar que muchos egresados se encuentran desempleados o trabajando como taxistas.
\end{abstract}

Este artículo presenta el análisis de los datos de un proyecto internacional de seguimiento de egresados en el que participaron nueve universidades mexicanas. Los datos revelan que efectivamente existen problemas de desempleo, pero también que las razones detrás de estos problemas son complejas y no siempre bien entendidas por los hacedores de políticas.

Palabras clave: egresados, educación superior, mercado laboral, México.

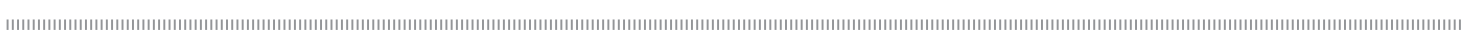

Profissionais do futuro ou futuros motoristas?

Os recém-formados e o mercado de trabalho no México

\section{Resumo}

A contribuição de uma universidade ao futuro de seus estudantes é ponto de controvérsia. Os relatórios oficiais normalmente representam à educação superior como o motor para o desenvolvimento econômico e social, mas ao mesmo tempo colocam em dúvida esta asseveração, ao destacar que muitos formados estão desempregados ou trabalhando como motoristas de taxi.

Este artigo apresenta a análise dos resultados de um projeto internacional de acompanhamento de recém-formados no qual participaram nove universidades mexicanas. Os dados revelam que efetivamente existem problemas de desemprego, mas também que as razões detrás destes problemas são complexas e nem sempre bem entendidas pelos geradores de políticas.

Palavras chave: recém-formados, educação superior, mercado de trabalho, México.

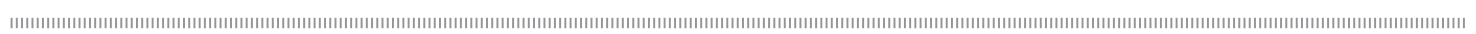

Wietse de Vries

wietsedevries@ultranet.com.mx

Doctor en Educación por la Universidad Autónoma de Aguascalientes. Profesor-investigador de tiempo completo en la Benemérita Universidad Autónoma de Puebla, México. Miembro del Sistema Nacional de Investigadores, nivel II. Temas de investigación: políticas públicas en educación superior, evaluación, financiamiento, efectos en actores (instituciones, académicos, estudiantes, egresados).

Yadira Navarro ynavarro@ultranet.com.mx

Doctora en Educación por la Universidad Autónoma de Aguascalientes. Profesora-investigadora de la Benemérita Universidad Autónoma de Puebla, México. Temas de investigación: el uso de tecnologías de información y comunicación, métodos de enseñanza-aprendizaje y cuestiones de género. 


\section{Abstract}

The contribution of universities to the future of its students is a controversial topic. Official reports usually profile higher education as the driver for economic and social development, but at the same time they cast doubt upon this assertion pointing out that many graduates are unemployed or work as taxi drivers.

This article presents the data analysis of an international project to follow-up on university graduates with the participation of nine Mexican universities. The data reveal that unemployment problems indeed exist, but also that the underlying reasons for these issues are complex and not always well understood by the policy makers.

Key words: university graduates, higher education, labor market, Mexico. 


\section{Introducción}

La educación superior mexicana ha estado envuelta, durante dos décadas, por un ambiente bipolar: en el polo maníaco u optimista, la educación superior es considerada como el eje central para el desarrollo económico y social del país, como la instancia indicada para resolver problemas de competitividad y empleo, o casi cualquier tema emergente (Task Force on Higher Education and Society, 2000; CEPAL-UNESCO, 1992). Bajo esta óptica, se estableció como una meta gubernamental aumentar la cobertura hasta el $30 \%$ en 2011 , amén de iniciativas para incorporar nuevos grupos de jóvenes. Este polo del debate enfatiza la importancia de aumentar el subsidio público, abrir más instituciones y carreras, introducir becas para estudiantes y mejorar la calidad de las instituciones públicas. Se suele observar que la universidad, a pesar de las recurrentes crisis económicas, sigue brindando importantes beneficios para aquel que logra terminar estudios terciarios (Flores y Muñoz, 2009).

Sin embargo, en el polo depresivo, encontramos declaraciones de distintos actores que plantean que las universidades aparentan ser más bien "fábricas de desempleo". A modo de ejemplo, en 2009, el subsecretario de Educación Superior observó que: "el 45 por ciento de los más de 7.8 millones de profesionistas nacionales no realizan actividades relacionadas con su carrera y se han tenido que conformar con trabajos de taxistas, comerciantes o empleos marginales" (La Jornada, 2009).

La tasa de desempleo entre recién egresados, según declaraciones oficiales, se situaría en alrededor del $11 \%$, tres veces más que la tasa de desempleo oficial entre la población económicamente activa (PEA) en general (Flores y Muñoz, 2009). Por si eso fuera poco, el mercado laboral para varias carreras estaría saturado, particularmente para opciones tradicionales como Administración, Contaduría, Medicina o Derecho (Cabrera et al., 2008).
Esta óptica también produjo diversas políticas para atender los problemas aparentes: se crearon nuevas instituciones, como las universidades tecnológicas y las politécnicas; hubo exhortaciones a las universidades públicas de limitar el ingreso a las carreras saturadas y de crear nuevas opciones, mejor orientadas hacia el mercado laboral. Al mismo tiempo, se desreguló la autorización de instituciones privadas. Al interior de las instituciones se fortaleció la infraestructura, se implementó el Programa del Mejoramiento de Profesores con el objetivo de contar con más profesores de tiempo completo con posgrado, y se revisaron los planes de estudio.

A raíz de estas acciones se produjeron cambios notables. En cuanto al crecimiento, la matrícula creció de un millón en 1990 hasta casi 2.5 millones de estudiantes en 2008, pasando de una tasa de cobertura del 16\% del grupo de edad (20-24 años) en 1990 hasta un $25 \%$ en 2010 (Rodríguez, 2010). Además de crecer, el sistema se diversificó de distintas maneras. La primera es institucional. Hacia finales de los ochenta, el sistema contaba con 719 instituciones, de las cuales 401 eran públicas y 318 privadas. A finales de 2005 ya existían 1892 instituciones, de las cuales 713 eran públicas y 1179 privadas. Si además incluimos a las sucursales, el sistema mexicano de educación superior cuenta actualmente con alrededor de 2500 instituciones registradas. Al mismo tiempo, la proporción de la matrícula atendida por el sector privado, que era del 18\% en 1990, llegó al 33\% en 2000 (De Vries y Álvarez, 2005), donde se estabilizó hasta 2010.

A la par, ha habido una enorme diversificación de carreras. Hasta 1990, una universidad pública solía tener una veintena de carreras y muchas universidades privadas nacieron ofreciendo de cuatro a cinco opciones. A partir de 1990, sin embargo, la oferta de muchas universidades - públicas y privadas- empezó a crecer para situarse por encima de 50 licenciaturas. Como resultado, mientras que al inicio de los noventa la Asociación Nacional 
de Universidades e Instituciones de Educación Superior (ANUIES) registraba 4038 programas de licenciatura y 1686 de posgrado, en 2005 había 7 849 licenciaturas y 3437 posgrados (De Vries y Álvarez, 2005).

Sin embargo, estos cambios no parecen haber resuelto la problemática relación entre la educación superior y el mercado laboral. Más bien, el crecimiento y la diversificación del sistema agregaron nuevos factores al debate (Machin y McNally, 2007). Si el sistema educativo se expandió rápidamente, ¿podemos explicar parte del problema del desempleo por una sobreoferta de egresados? En cuanto a su preparación, ¿están sobrecalificados los egresados o existe un resquicio entre lo aprendido y lo requerido por el mercado laboral? ¿Existen diferencias por áreas de conocimiento? ¿Están los estudiantes eligiendo las carreras equivocadas? ¿Sigue influyendo el género? ¿Hasta dónde impacta el pasado familiar? ¿Hasta qué punto influye el tipo de institución en que el egresado se formó?

Para responder a estas interrogantes, revisaremos en este artículo cuál ha sido la suerte de los egresados de nueve universidades mexicanas. En la primera parte analizaremos datos generales sobre el empleo; en la segunda, revisaremos los distintos factores que podrían influir sobre la situación en el mercado laboral.

\section{Metodología}

Este artículo explora los interrogantes antes expuestos a partir de un proyecto de investigación internacional llamado "El profesional flexible en la sociedad del conocimiento" o PROFLEX. Este proyecto retoma la experiencia del seguimiento de egresados en la Unión Europea, llamado REFLEX, ("The flexible professional in the knowledge society new demands on higher education in Europe").

Desde 2006, PROFLEX, bajo la coordinación de la Universidad Politécnica de Valencia, ha incorporado a más de 50 instituciones latinoamericanas y se han aplicado más de 10 mil cuestionarios. En el caso mexicano, participaron nueve universidades, tres privadas y seis públicas: por un lado, la Universidad del Valle de México, la Universidad La Salle y el Centro de Enseñanza Técnica y Superior (CETYS)-Universidad, y por el otro, las universidades públicas estatales de Guadalajara, San Luís Potosí, Nuevo León, Puebla y Veracruz, y el Instituto Tecnológico de Sonora.

Las universidades mexicanas participantes en el proyecto representan una parte importante de la matrícula nacional: se trata de universidades públicas y privadas de mediano a gran tamaño, casi todas con más de 50 mil estudiantes de licenciatura.

En el caso mexicano, se aplicaron 4260 cuestionarios a los egresados de licenciatura (ISCED 5A). Para fines comparativos internacionales, se entrevistaron personas que habían egresado cinco años atrás: los cuestionarios se aplicaron en 2007 y 2008, a aquellos que habían terminado sus estudios en 2002 y 2003. Se trata de un muestreo aleatorio estratificado, proporcional a la población por área geográfica y área de estudio de cada universidad. Para cada universidad se definió una muestra representativa a partir del egreso reportado en 2002 y 2003. El margen de error es de $\pm 0.311 \%$ para los datos globales, considerando $p=q$ y un margen de confianza del 95.5 por ciento.

La encuesta se realizó por medio de un cuestionario de preguntas cerradas. La aplicación se efectuó vía entrevistas telefónicas, visitas domiciliarias y a través de una página web.

\section{Limitaciones}

En primer lugar, la muestra no considera datos sobre algunos sectores del sistema educativo mexicano, como las universidades tecnológicas, los institutos tecnológicos o el amplio sector de pequeñas universidades privadas.

En segundo lugar, la muestra es confiable por áreas de conocimiento, pero no en cuanto a las 
carreras específicas. Un problema importante para estudios de egresados consiste en que casi todas las universidades de tamaño medio o grande actualmente ofrecen más de 50 opciones de licenciatura, algunas con pocos estudiantes y egresados, lo cual complica organizar un estudio representativo para todas las opciones. La agrupación de carreras sigue la acostumbrada en la Unión Europea.

\section{El mercado de trabajo}

A la luz de los datos alarmantes sobre el desempleo de los egresados mexicanos, la pregunta más apremiante es: ¿efectivamente preparan las universidades para el desempleo?

La tabla 1 revela que efectivamente existe un problema de desempleo. Del total de los entrevistados, el $14.5 \%$ no tenía un trabajo remunerado en el momento de la entrevista, lo cual concuerda con los datos alarmantes. En comparación con otros países donde se aplicó PROFLEX, México reporta el mayor desempleo: la media europea es del 10.0\%, la de América Latina del 11.4\% (Mora et al., 2010).

Tabla 1. Porcentaje de graduados en situación de desempleo (tasa bruta), por país y área de estudio

\begin{tabular}{|c|c|c|c|c|c|c|c|c|c|}
\hline País & España & Francia & Alemania & $\begin{array}{l}\text { Reino } \\
\text { Unido }\end{array}$ & Europa & Chile & México & $\begin{array}{c}\text { América } \\
\text { Latina }\end{array}$ & Japón \\
\hline Promedio por país & $12.5 \%$ & $12.7 \%$ & $9.4 \%$ & $10.3 \%$ & $10.0 \%$ & $9.0 \%$ & $14.5 \%$ & $11.4 \%$ & $10.5 \%$ \\
\hline Educación & $14.7 \%$ & $8.9 \%$ & $7.8 \%$ & $2.0 \%$ & $12.0 \%$ & $6.2 \%$ & $12.7 \%$ & $7.1 \%$ & $11.9 \%$ \\
\hline Humanidades & $20.4 \%$ & $19.0 \%$ & $13.2 \%$ & $17.3 \%$ & $15.4 \%$ & $16.9 \%$ & $15.4 \%$ & $15.3 \%$ & $12.9 \%$ \\
\hline Ciencias Sociales & $12.3 \%$ & $15.3 \%$ & $11.3 \%$ & $13.5 \%$ & $10.5 \%$ & $11.1 \%$ & $15.1 \%$ & $11.8 \%$ & $11.4 \%$ \\
\hline $\begin{array}{l}\text { Economía y } \\
\text { empresa }\end{array}$ & $10.5 \%$ & $7.9 \%$ & $3.9 \%$ & $7.4 \%$ & $7.8 \%$ & $7.9 \%$ & $10.9 \%$ & $10.1 \%$ & $11.0 \%$ \\
\hline Derecho & $17.3 \%$ & $17.7 \%$ & $13.7 \%$ & $14.3 \%$ & $12.9 \%$ & $12.7 \%$ & $14.1 \%$ & $12.1 \%$ & $11.7 \%$ \\
\hline Técnicas & $7.9 \%$ & $7.7 \%$ & $7.4 \%$ & $8.2 \%$ & $6.2 \%$ & $6.9 \%$ & $10.0 \%$ & $8.6 \%$ & $7.0 \%$ \\
\hline Salud & $5.8 \%$ & $7.5 \%$ & $9.6 \%$ & $8.0 \%$ & $9.2 \%$ & $4.3 \%$ & $16.1 \%$ & $11.0 \%$ & $11.8 \%$ \\
\hline Ciencias & $15.5 \%$ & $16.9 \%$ & $15.3 \%$ & $8.8 \%$ & $13.1 \%$ & $23.2 \%$ & $27.0 \%$ & $22.8 \%$ & $11.5 \%$ \\
\hline Número entrevistas & 5384 & 1614 & 1667 & 1397 & 36973 & 2846 & 3992 & 8295 & 2073 \\
\hline
\end{tabular}

Fuente: datos REFLEX Y PROFLEX. 


\section{Tasas netas y brutas}

Los datos mencionados arriba, sin embargo, reflejan tasas brutas de desempleo: simplemente reportan a los que no están trabajando. Como tal, incluyen a personas sin empleo que posiblemente no buscan trabajo. Por ejemplo, el $38.6 \%$ de los entrevistados reporta haber seguido estudios de posgrado, lo cual podría implicar que pospusieron su ingreso al mercado de trabajo. Sin embargo, al revisar los datos de los egresados, no parece ser así: de los que siguieron estudios posteriores, el $14 \%$ reporta no estar trabajando, pero el porcentaje es igual para los que no emprendieron estudios de posgrado.

Una forma distinta de medir el desempleo es la tasa neta o el desempleo abierto, que contabiliza sólo aquellos desempleados que indican estar buscando trabajo. Al considerar solamente aquéllos, México reporta una tasa de desempleo de la PEA en general del 4.32\% (El Economista, 2009), la menor dentro de la Organización para la Cooperación y el Desarrollo Económicos (OCDE). Si consideramos este criterio para los egresados universitarios, la tasa de desempleo baja hasta el 6.6\%. Así, se sitúa en el mismo orden que en otros países.

En términos de desempleo, México muestra problemas serios, aunque no tan graves como algunas declaraciones indican. Sin embargo, resulta preocupante que México presenta las mayores tasas de desempleo para egresados, al mismo tiempo que registra la menor cobertura en educación superior, dentro de la muestra de países que participaron en PROFLEX.

\section{Diferencias por áreas}

Por otra parte, la tabla 1 indica que hay diferencias importantes entre áreas del conocimiento. La tasa bruta de desempleo llega hasta el $27 \%$ en el caso de las Ciencias, frente al $10 \%$ en el caso de Técnicas. Obviamente, operan diferentes lógicas: las carreras técnicas suelen preparar directamente para el mercado laboral, mientras que en las ciencias se suele seguir hacia el posgrado.
En comparación internacional, algunas áreas tienen datos similares. La tasa de desempleo es alta en Humanidades en prácticamente todos los países. Sin embargo, tres áreas destacan como problemáticas en el caso mexicano: Técnicas, Salud y Ciencias.

Se pueden observar además serios problemas en el mercado laboral si consideramos las tasas netas de desempleo. En Economía y Empresas la tasa neta se sitúa en 5\%, en las Técnicas en $5.4 \%$, en Salud en $5.7 \%$. En el otro extremo, las Sociales tienen un desempleo abierto de $7.9 \%$, las Humanidades un $8.2 \%$, y las Ciencias $12.8 \%$. En un nivel intermedio están Derecho con $6.8 \%$ y Educación con 6.7 por ciento.

Estos datos contradicen los señalamientos públicos acerca de la saturación de las carreras tradicionales y la necesidad de reorientar a los estudiantes hacia sectores como las Ciencias. Llama la atención que las áreas de menor matrícula (Humanidades, Ciencias) demuestran las tasas netas más elevadas de desempleo, un dato que coincide con estudios anteriores en el caso mexicano (Cabrera et al., 2008).

\section{Los salarios}

Sin embargo, es posible que algunas áreas ofrezcan mayores oportunidades de empleo, pero con salarios inferiores. Para ello, comparamos los ingresos mensuales reportados por área de estudio.

El área peor pagada es Educación, seguida por Salud y Ciencias. En cambio, Economía y Empresa, las carreras Técnicas y, sobre todo, Derecho, tienen mejores remuneraciones. Cabe reparar que puede haber diferencias importantes incluso al interior de cada área. Como señalábamos anteriormente, la muestra no admite comparaciones confiables entre carreras individuales, solamente por áreas de conocimiento. Sin embargo, dentro del área de la Salud, los médicos suelen obtener ingresos más elevados que las enfermeras.

Aún así, los salarios promedio de los egresados mexicanos son mucho más bajos que en otros países, incluso en América Latina. Según 
los datos de PROFLEX, el salario promedio mensual de un egresado universitario en México se sitúa en 859 dólares de Estados Unidos (US\$) (en 960 US $\$$ con trabajos adicionales), frente a 1703 US\$ en Chile o 1752 US\$ en Uruguay (Mora et al., 2010).

Se puede argumentar que el salario de un egresado en México es más bajo, porque labora en un país donde los salarios en general son bajos. Para comprobar esta conjetura, comparamos los salarios con el Producto Interno Bruto (PIB) per capita, ajustando los montos por la Paridad de Poder
Adquisitivo (PPA), un factor que toma en cuenta el costo de vida.

Los egresados mexicanos ganan poco en comparación con sus colegas en otros países, pero reciben el 21.59\% más que el PIB per capita, ajustado por PPA. Así, los egresados reciben ingresos muy superiores a los de sus contemporáneos sin estudios superiores, en un contexto nacional en el que alrededor de la tercera parte de los jóvenes se encuentra sin trabajo o ha conseguido trabajo pero en condiciones tan precarias que sigue viviendo por debajo de la línea de pobreza (Márquez, 2008).

Tabla 2. ¿Cuál es aproximadamente tu sueldo mensual bruto?

Sueldo base regular (pesos mexicanos de 2008)

\begin{tabular}{|l|c|c|}
\hline \multicolumn{1}{|c|}{ Área } & Media & Número \\
\hline Educación & 6413 & 405 \\
\hline Humanidades & 7552 & 57 \\
\hline Ciencias Sociales & 8941 & 484 \\
\hline Economía y Empresa & 8960 & 766 \\
\hline Derecho & 13581 & 326 \\
\hline Técnicas & 9108 & 717 \\
\hline Salud & 6536 & 346 \\
\hline Ciencias & 6558 & 286 \\
\hline Total & 8655 & 3386 \\
\hline
\end{tabular}

Fuente: datos PROFLEX.

Tabla 3. Ingresos anuales comparados con el PIB per capita

\begin{tabular}{|c|c|c|c|c|c|c|c||}
\hline País & España & Francia & Alemania & Reino Unido & Chile & México & Japón \\
\hline $\begin{array}{c}\text { PIB per capita, US\$, } \\
\text { PPA, 2007 }\end{array}$ & 31783 & 33102 & 34864 & 35455 & 14135 & 14462 & 34352 \\
\hline $\begin{array}{c}\text { Salario anual } \\
\text { reportado en US\$, } \\
\text { PPA, 2008 }\end{array}$ & 23525 & 28313 & 52857 & 34297 & 32333 & 17567 & 33023 \\
\hline $\begin{array}{c}\text { Salario anual } \\
\text { egresado/PIB per } \\
\text { capita, PPA* 100 }\end{array}$ & 74.0 & 85.5 & 151.6 & 96.7 & 228.7 & 121.5 & 96.1 \\
\hline $\begin{array}{l}\text { Salario anual calculado a partir de encuestas REFLEX y PROFLEX, con ingreso } \\
\text { reportado en 2008. Datos del PIB per capita, PPA: UNDP (2010). }\end{array}$ \\
\hline
\end{tabular}




\section{Tipo de trabajo actual}

El hecho de que los salarios sean bajos puede derivarse de que los egresados se ven obligados a aceptar puestos que no corresponden a sus estudios. Es decir, posiblemente trabajan como taxistas.

Cabe preguntarse entonces en qué tipo de puestos están trabajando los egresados. La tabla 4 indica que la mayoría de los puestos se corresponden con estudios universitarios. E1 15\% ha llegado a ocupar puestos directivos, mientras que el $45 \%$ trabaja como profesional científico.
Sin embargo, esta descripción de puestos es muy general. Revisamos si el trabajo corresponde con su nivel de estudios y con el tipo de estudios que cursaron.

Para la inmensa mayoría de los egresados, su trabajo actual requiere de estudios de licenciatura o superiores. Sólo el 5.2\% indica que su trabajo no requiere de ellos. Así, no parece darse el fenómeno de que los egresados se vean obligados a aceptar puestos que no corresponden a sus estudios, como taxista. Más bien, llama la atención que

Tabla 4. ¿Cuál es tu ocupación o puesto?

\begin{tabular}{|l|c|c|}
\hline \multicolumn{1}{|c|}{ Puesto } & Frecuencia & Porcentaje \\
\hline Directivo & 504 & $15.4 \%$ \\
\hline $\begin{array}{l}\text { Profesional } \\
\text { cientifico }\end{array}$ & 1464 & $44.8 \%$ \\
\hline $\begin{array}{l}\text { Técnico de } \\
\text { nivel medio }\end{array}$ & 432 & $13.2 \%$ \\
\hline $\begin{array}{l}\text { Empleado } \\
\text { de oficina }\end{array}$ & 636 & $19.5 \%$ \\
\hline Otros & 234 & $7.2 \%$ \\
\hline Total & 3271 & $100.0 \%$ \\
\hline
\end{tabular}

Fuente: datos PROFLEX.

Tabla 5. Según tu opinión ¿cuál es el nivel de estudios más apropiado para el trabajo que realizas?

\begin{tabular}{|l|r|r|}
\hline \multicolumn{1}{|c|}{ Nivel apropiado } & \multicolumn{1}{|c|}{ Frecuencia } & \multicolumn{1}{c|}{ Porcentaje } \\
\hline Doctorado & 112 & $3.2 \%$ \\
\hline Maestría & 852 & $24.2 \%$ \\
\hline Especialidad & 675 & $19.2 \%$ \\
\hline Licenciatura & 1701 & $48.3 \%$ \\
\hline $\begin{array}{l}\text { No es necesario tener estudios } \\
\text { universitarios }\end{array}$ & 184 & $5.2 \%$ \\
\hline Total & 3523 & $100.0 \%$ \\
\hline
\end{tabular}

Fuente: datos PROFLEX. 
poco menos de la mitad de los entrevistados indica que su trabajo precisa de estudios de posgrado.

Lo anterior se confirma cuando preguntamos por el área más apropiada para su trabajo. Para el 87\% de los entrevistados, su puesto requiere de una preparación como la de su área de estudios o semejante. Sólo el 5.6\% indica que no requiere estudios de ningún área en particular. Sin embargo, es posible que la forma de trabajo haya cambiado. El mercado laboral tradicional se caracterizaba por egresados de las carreras tradicionales que ejercían su profesión de manera independiente, o que ingresaban a las filas del aparato estatal. Las permutas políticas y económicas harían suponer que esta situación ha cambiado sustancialmente: ha habido una reducción del Estado como empleador, tanto por la reducción de puestos de funcionarios como por la privatización de empresas estatales. Al mismo tiempo, el tradicional ejercicio independiente podría haber sido remplazado por personal contratado por empresas. Aunque se han producido cambios, los datos indican que no son tan grandes como haría suponer la literatura.

Tabla 6. Según tu opinión, ¿cuál es el área de estudio más apropiada para este trabajo?

Fuente: datos PROFLEX.

\begin{tabular}{|l|r|r|}
\hline Área apropiada & Frecuencia & Porcentaje \\
\hline $\begin{array}{l}\text { Exclusivamente } \\
\text { tu propia área } \\
\text { de estudios }\end{array}$ & 1153 & $32.9 \%$ \\
\hline $\begin{array}{l}\text { Tu propia área } \\
\text { o alguna } \\
\text { relacionada }\end{array}$ & 1896 & $54.1 \%$ \\
\hline $\begin{array}{l}\text { Un área } \\
\text { totalmente } \\
\text { diferente }\end{array}$ & 262 & $7.5 \%$ \\
\hline $\begin{array}{l}\text { Ningún área en } \\
\text { particular }\end{array}$ & 195 & $5.6 \%$ \\
\hline Total & 3506 & $100.0 \%$ \\
\hline
\end{tabular}

Tabla 7. ¿Trabajas por cuenta propia?

\begin{tabular}{|l|l|r|r|r|}
\hline \multicolumn{1}{|c|}{ Area } & \multicolumn{1}{c|}{ Si } & \multicolumn{1}{c|}{ No } & Total \\
\hline Educación & $5.90 \%$ & $94.10 \%$ & $100 \%$ \\
\hline Humanidades & $27.40 \%$ & $72.60 \%$ & $100 \%$ \\
\hline Ciencias Sociales & $16.80 \%$ & $83.20 \%$ & $100 \%$ \\
\hline Economia y Empresas & $16.30 \%$ & $83.70 \%$ & $100 \%$ \\
\hline Derecho & $32.50 \%$ & $67.50 \%$ & $100 \%$ \\
\hline Técnicas & $19.60 \%$ & $80.40 \%$ & $100 \%$ \\
\hline Salud & $38.40 \%$ & $61.60 \%$ & $100 \%$ \\
\hline Ciencias & $9.20 \%$ & $90.80 \%$ & $100 \%$ \\
\hline Total & $21.20 \%$ & $78.80 \%$ & $100 \%$ \\
\hline
\end{tabular}

Fuente: datos PROFLEX. 
En áreas como Derecho y Salud, más del 30\% de los egresados trabaja por cuenta propia (como trabajo principal). En el caso de las Humanidades, la cifra llega a 27\%. Es decir, permanece en gran medida el panorama donde los contadores, abogados, dentistas o médicos establecen su propio consultorio o despacho para prestar sus servicios. Dentro del conjunto de países que participaron en PROFLEX, México registra el porcentaje más alto de egresados que trabajan por cuenta propia, con un $21.2 \%$, frente a Chile (10.8\%) o España (9.2\%).
El 30\% de los egresados trabaja en el sector público. En el caso de Derecho y de Salud, sigue habiendo un gran porcentaje de empleados públicos, lo cual es consistente con un empleo en la burocracia, y con el hecho de que gran parte de la atención médica en México sigue siendo pública. Debe llamar la atención, sin embargo, que tanto los egresados de Educación como los de Ciencias están encontrando empleo mayoritariamente en el sector privado, no obstante que la educación y la investigación científica solían ser un terreno dominado por el sector público.

Tabla 8. ¿A qué sector pertenece tu organización?

\begin{tabular}{|c|c|c|c|c|c|}
\hline Área & Público & $\begin{array}{l}\text { Privado sin fines de } \\
\text { lucro }\end{array}$ & Privado & Otros & Total \\
\hline Educación & $40.0 \%$ & $6.1 \%$ & $50.4 \%$ & $3.5 \%$ & $100 \%$ \\
\hline Humanidades & $30.5 \%$ & $1.8 \%$ & $67.3 \%$ & $0.5 \%$ & $100 \%$ \\
\hline $\begin{array}{l}\text { Ciencias } \\
\text { Sociales }\end{array}$ & $27.4 \%$ & $4.2 \%$ & $66.5 \%$ & $1.8 \%$ & $100 \%$ \\
\hline $\begin{array}{l}\text { Economía y } \\
\text { Empresa }\end{array}$ & $19.5 \%$ & $3.0 \%$ & $76.8 \%$ & $0.7 \%$ & $100 \%$ \\
\hline Derecho & $48.8 \%$ & $0.8 \%$ & $49.3 \%$ & $1.0 \%$ & $100 \%$ \\
\hline Técnicas & $21.6 \%$ & $4.3 \%$ & $72.7 \%$ & $1.4 \%$ & $100 \%$ \\
\hline Salud & $54.3 \%$ & $2.4 \%$ & $42.1 \%$ & $1.2 \%$ & $100 \%$ \\
\hline Ciencias & $33.1 \%$ & $4.9 \%$ & $60.7 \%$ & $1.2 \%$ & $100 \%$ \\
\hline Total & $29.9 \%$ & $3.3 \%$ & $65.6 \%$ & $1.2 \%$ & $100 \%$ \\
\hline
\end{tabular}

Fuente: datos PROFLEX. 


\section{Posibles factores de influencia}

En esta segunda parte revisaremos factores que pueden influir en el desempeño laboral de los egresados. Consideramos varios factores, como las competencias con que cuenta el egresado, el tipo de institución, el género o los antecedentes familiares.

\section{Competencias}

Una interrogante importante es si los resultados en el mercado laboral se deben a la falta de competencias. Al final de cuentas, varios expertos (Castells, 2004; Perrenoud, 1999) señalan que puede existir un desfase crucial entre las competencias adquiridas en la universidad y las que el mercado laboral exige. Igualmente, varias universidades han reformado sus currículos para incluir competencias, aunque no queda claro si se trata de adaptarse al mercado o a una nueva moda educativa (Díaz-Barriga, 2006). Para revisar este aspecto, el cuestionario PROFLEX solicita al egresado evaluar su propio nivel de competencia, el nivel que exige su trabajo y la aportación que hizo la universidad. El cuestionario contempla $19 \mathrm{com}$ petencias. La tabla refleja las evaluaciones de los egresados, ordenadas de menos a más importantes, en el terreno de las exigencias laborales.

Tabla 9. Competencias propias, exigidas y aprendidas en la universidad

\begin{tabular}{|l|c|c|c|}
\hline \multicolumn{1}{|c|}{ Competencia } & $\begin{array}{c}\text { Nivel } \\
\text { propio } \\
\text { (media) }\end{array}$ & $\begin{array}{c}\text { Nivel } \\
\text { requerido en } \\
\text { el trabajo } \\
\text { (media) }\end{array}$ & $\begin{array}{c}\text { Aportación } \\
\text { universidad } \\
\text { (media) }\end{array}$ \\
\hline Capacidad para escribir y hablar en idiomas extranjeros & 4.1 & 4.2 & 3.5 \\
\hline Conocimientos de otras áreas o disciplinas & 4.7 & 5.0 & 4.5 \\
\hline Predisposición para cuestionar ideas propias o ajenas & 5.4 & 5.3 & 4.9 \\
\hline Capacidad para presentar en público productos, ideas o informes & 5.4 & 5.4 & 5.0 \\
\hline Capacidad para movilizar las capacidades de otros & 5.4 & 5.4 & 4.8 \\
\hline Capacidad para detectar nuevas oportunidades & 5.4 & 5.5 & 4.8 \\
\hline Capacidad para redactar informes o documentos & 5.5 & 5.5 & 5.0 \\
\hline Dominio de tu área o disciplina & 5.3 & 5.5 & 5.0 \\
\hline \hline Capacidad para negociar de forma eficaz & 5.4 & 5.5 & 4.7 \\
\hline Pensamiento analítico & 5.4 & 5.5 & 5.1 \\
\hline Capacidad para utilizar herramientas informáticas & 5.7 & 5.6 & 4.9 \\
\hline Capacidad para hacer valer tu autoridad & 5.6 & 5.6 & 4.8 \\
\hline Capacidad para adquirir con rapidez nuevos conocimientos & 5.8 & 5.6 & 5.2 \\
\hline \hline Capacidad para coordinar actividades & 5.7 & 5.7 & 5.0 \\
\hline Capacidad para encontrar nuevas ideas y soluciones & 5.7 & 5.7 & 5.0 \\
\hline Capacidad para trabajar en equipo & 5.8 & 5.7 & 5.3 \\
\hline Capacidad para usar el tiempo de forma efectiva & 5.6 & 5.7 & 5.0 \\
\hline Capacidad para hacerte entender & 5.6 & 5.8 & 5.1 \\
\hline Capacidad para aplicar los conocimientos en la práctica & 5.8 & 5.8 & 5.1 \\
\hline \hline Capacidad para trabajar bajo presión & 5.8 & 5.8 & 5.1 \\
\hline Capacidad para tomar decisiones & 6.0 & 5.9 & 5.0 \\
\hline
\end{tabular}

Escala Likert de 1 (nada) a 7 (mucho)

Fuente: datos PROFLEX. 
Un aspecto que resalta en este rubro es que los egresados reportan niveles de competencias que coinciden con -o que en ocasiones rebasan- lo requerido por el mercado laboral. Indican también que no todo se aprendió en la universidad, pero que, por lo general, poseen niveles suficientes.

Un segundo aspecto interesante es que las habilidades "prácticas" son calificadas como más importantes; desde la capacidad para tomar decisiones (que recibe la calificación más alta) hasta la capacidad de coordinar actividades. Aspectos como el dominio de la disciplina o la capacidad de escribir informes reciben una calificación menor. Finalmente, resalta que varias competencias que han sido enfatizadas tanto por el gobierno federal como por la mayoría de las universidades, resultan ser las menos importantes para el trabajo: para empezar, el dominio de un segundo idioma (generalmente el inglés) es la competencia menos exigida. Le sigue el conocimiento de otras áreas (la interdisciplinariedad) y la predisposición de cuestionar ideas ajenas o propias (el pensamiento crítico).

El hecho de que los egresados indican tener un nivel suficiente de competencias frente a las demandas de su trabajo, pero que solamente aprendieron parte de estas competencias en la universidad, hace preguntar en dónde adquirieron la parte adicional. Una primera explicación es que ya poseían ciertas competencias antes de ingresar a la universidad. Una segunda es que la educación no termina al egresar. En efecto, según la encuesta, dos terceras partes de los egresados realizaron alguna actividad de capacitación en el trabajo durante el año anterior a la entrevista.

Así, no parece existir un desfase entre las competencias que aprendió o adquirió el egresado y las exigencias del mercado laboral. Cabe resaltar, sin embargo, que permanecen discrepancias entre lo que la práctica laboral realmente exige y lo que distintos actores proclaman como necesario: a modo de ejemplo, el dominio del inglés recibe mucho énfasis desde la educación básica, opera como criterio de admisión para algunas universidades y suele aparecer como exigencia en el proceso de contratación laboral. Sin embargo, resulta ser la competencia menos valorada en el trabajo cotidiano para la mayoría de los egresados.

\section{Diferencias entre instituciones}

Nuestra muestra incluye seis universidades públicas estatales y tres universidades privadas. ¿Podemos observar diferencias importantes entre ambos sectores? Un primer dato sobresaliente es que los egresados del sector privado reportan ingresos cuatro veces mayores que los del sector público. Del mismo modo, hay diferencias en la tasa de empleo entre los egresados del sector público y del privado (véase tabla 12).

De acuerdo con estos datos, el desempleo es más grave para egresados de las universidades públicas que de las privadas. Así, nuestros datos confirman las conclusiones de otros estudios (Muñoz, 1996) en el sentido de que el sistema educativo mexicano parece exaltar las desigualdades sociales en vez de atenuarlas. Cabe recordar que la muestra solamente incluye algunas de las principales universidades públicas estatales, y algunas universidades privadas consideradas de "élite". Así, los problemas de desempleo y las desigualdades pueden ser más graves en otros sectores.

Es menester marcar también que la fuerte diferencia entre los sectores privado y público solamente se presenta en el caso mexicano. En los demás países participantes en PROFLEX no se evidencian diferencias importantes entre tipos de institución. Eso se puede explicar en parte por el hecho que en muchos países europeos no existe un sector privado de "élite". Eso plantea la pregunta de por qué países europeos lograron una cobertura por encima del $50 \%$ del grupo de edad, sin tener una estratificación institucional semejante. Una posible explicación es la distribución de la riqueza: la distribución, medida por el coeficiente GINI, es marcadamente 
distinta: México registra 46.1, España 34.7, Alemania 28.3 (UNDP, 2010). Así, en México existe una élite económica, que puede explicar la existencia de un sector educativo de élite.

En cuanto a los puestos (tabla 12), nuevamente se presentan diferencias: los egresados de las universidades públicas indican estar trabajando en su mayoría (58\%) como profesionales científicos, mientras que sólo el $22.3 \%$ de los egresados de las privadas lo hacen. Cuando se trata de puestos directivos, el $7.4 \%$ de los egresados del sector público se califica así, frente al $30.6 \%$ del sector privado.

Tabla 10. ¿Cuál es aproximadamente tu sueldo mensual bruto? Sueldo base regular (pesos mexicanos de 2008). Sector privado y público

\begin{tabular}{|l|r|r|}
\hline \multicolumn{1}{|c|}{ Sector de egreso } & \multicolumn{1}{|c|}{ Media } & Número \\
\hline \hline Universidad pública & 4375.3 & 2478 \\
\hline Universidad privada & 20300.7 & 910 \\
\hline Total & 8651.2 & 3388 \\
\hline
\end{tabular}

Fuente: datos PROFLEX.

Tabla 11. Diferencias en empleo entre sectores

\begin{tabular}{|l|l|r|r|r|}
\hline \multicolumn{2}{|c|}{$\begin{array}{c}\text { ¿Actualmente tienes } \\
\text { trabajo remunerado? }\end{array}$} & Universidad pública & Universidad privada & Total \\
\hline \hline \multirow{2}{*}{ Sí, tengo un trabajo } & Número & 2341 & 932 & 3273 \\
\cline { 2 - 6 } & $\%$ & $75.3 \%$ & $81.0 \%$ & $76.8 \%$ \\
\hline \multirow{2}{*}{$\begin{array}{l}\text { Sí, tengo más de un } \\
\text { trabajo }\end{array}$} & Número & 291 & 103 & 394 \\
\hline \hline \multirow{2}{*}{ No } & $\%$ & $9.4 \%$ & $8.9 \%$ & $9.2 \%$ \\
\hline \hline \multirow{2}{*}{ Total } & Número & 477 & 116 & 593 \\
\hline & $\%$ & $15.3 \%$ & $10.1 \%$ & $13.9 \%$ \\
\hline
\end{tabular}

Fuente: datos PROFLEX. 
Tabla 12. Ocupación o puesto por sectores

\begin{tabular}{|c|c|c|c|c|}
\hline \multirow{2}{*}{\multicolumn{2}{|c|}{ Ocupación o puesto }} & \multicolumn{2}{|c|}{ Sector } & \multirow{3}{*}{$\begin{aligned} & \text { Total } \\
& 450 \\
&\end{aligned}$} \\
\hline & & \multirow{2}{*}{$\begin{array}{r}\begin{array}{c}\text { Universidad } \\
\text { pública }\end{array} \\
181\end{array}$} & \multirow{2}{*}{\begin{tabular}{|r|}
$\begin{array}{c}\text { Universidad } \\
\text { privada }\end{array}$ \\
269
\end{tabular}} & \\
\hline \multirow{2}{*}{ Directivos } & Número & & & \\
\hline & $\%$ & $7.4 \%$ & $30.6 \%$ & $13.5 \%$ \\
\hline \multirow{2}{*}{$\begin{array}{l}\begin{array}{l}\text { Profesional } \\
\text { científico }\end{array} \\
\end{array}$} & Número & 1430 & 196 & 1626 \\
\hline & $\%$ & $58.1 \%$ & $22.3 \%$ & $48.7 \%$ \\
\hline \multirow{2}{*}{\begin{tabular}{|l|} 
Técnico de \\
nivel \\
medio
\end{tabular}} & Número & 357 & 105 & 462 \\
\hline & $\%$ & $14.5 \%$ & $12.0 \%$ & $13.8 \%$ \\
\hline \multirow{2}{*}{$\begin{array}{l}\text { Empleado } \\
\text { de oficina }\end{array}$} & Número & 316 & 283 & 599 \\
\hline & $\%$ & $12.8 \%$ & $32.2 \%$ & $17.9 \%$ \\
\hline \multirow{2}{*}{ Otros } & Número & 178 & 25 & 203 \\
\hline & $\%$ & $7.2 \%$ & $2.8 \%$ & $6.1 \%$ \\
\hline \multirow{3}{*}{ Total } & Número & 2462 & 878 & 3340 \\
\hline & $\%$ & $100.0 \%$ & $100.0 \%$ & $100.0 \%$ \\
\hline & \begin{tabular}{|l}
$\%$ del \\
Total
\end{tabular} & $73.7 \%$ & $26.3 \%$ & $100.0 \%$ \\
\hline
\end{tabular}

Fuente: datos PROFLEX.

Tabla 13. Sector al que pertenece la empresa donde trabajas, en porcentajes

\begin{tabular}{|l|r|r|}
\hline \multicolumn{1}{|c|}{$\begin{array}{c}\text { Sector } \\
\text { económico }\end{array}$} & $\begin{array}{c}\text { Universidad } \\
\text { Pública }\end{array}$ & \multicolumn{1}{c|}{$\begin{array}{c}\text { Universidad } \\
\text { Privada }\end{array}$} \\
\hline Público & $35.5 \%$ & $19.6 \%$ \\
\hline Privado sin lucro & $2.8 \%$ & $4.2 \%$ \\
\hline Privado & $60.0 \%$ & $75.3 \%$ \\
\hline Otros & $1.6 \%$ & $0.8 \%$ \\
\hline
\end{tabular}

Fuente: datos PROFLEX. 
Los puestos directivos están destinados en mayor proporción a los egresados de universidades privadas y las oportunidades para el sector público están en el ámbito científico profesional. Al mismo tiempo, el $75 \%$ de los egresados de las universidades privadas trabajan en empresas privadas, más que los egresados de las públicas $(60 \%)$.
En cuanto al tamaño de la empresa, el 24.4\% de los egresados de la universidad pública indica trabajar en una empresa con más de mil empleados o trabajadores, frente al $40.7 \%$ de los egresados del sector privado.

Las diferencias hacen pensar que los dos sectores podrían ofrecer formaciones distintas. Sin embargo, según los datos, no es así.

Tabla 14. ¿En qué medida se hacía énfasis en tu carrera en los siguientes métodos de enseñanza y aprendizaje?

\begin{tabular}{|c|c|c|c|}
\hline Métodos & $\begin{array}{l}\text { Universidad } \\
\text { pública }\end{array}$ & $\begin{array}{l}\text { Universidad } \\
\text { privada }\end{array}$ & Total \\
\hline Asistencia a clase & 4.1 & 4.3 & 4.2 \\
\hline $\begin{array}{l}\text { Teorías, conceptos y } \\
\text { paradigmas }\end{array}$ & 3.9 & 3.8 & 3.9 \\
\hline Trabajos escritos & 3.8 & 4.1 & 3.9 \\
\hline Trabajos en grupo & 3.7 & 4.2 & 3.9 \\
\hline Exposiciones orales & 3.7 & 4.0 & 3.8 \\
\hline $\begin{array}{l}\text { Estudio personal (o } \\
\text { trabajo autónomo) }\end{array}$ & 3.7 & 3.6 & 3.6 \\
\hline $\begin{array}{l}\text { Conocimientos prácticos y } \\
\text { metodológicos }\end{array}$ & 3.6 & 3.5 & 3.6 \\
\hline $\begin{array}{l}\text { El profesor era la principal } \\
\text { fuente de información }\end{array}$ & 3.6 & 3.7 & 3.6 \\
\hline $\begin{array}{l}\text { Aprendizaje basado en } \\
\text { proyectos o problemas }\end{array}$ & 3.4 & 3.5 & 3.5 \\
\hline $\begin{array}{l}\text { Participación en } \\
\text { proyectos de } \\
\text { investigación }\end{array}$ & 3.3 & 3.6 & 3.4 \\
\hline $\begin{array}{l}\text { Realización de exámenes } \\
\text { de opción múltiple }\end{array}$ & 3.1 & 3.1 & 3.1 \\
\hline $\begin{array}{l}\text { Prácticas en empresas, } \\
\text { instituciones o similares }\end{array}$ & 2.8 & 2.7 & 2.7 \\
\hline
\end{tabular}


Tabla 15. Egresados por área de conocimiento

\begin{tabular}{|c|c|c|c|c|}
\hline \multirow{2}{*}{\multicolumn{2}{|c|}{ Área }} & \multicolumn{2}{|c|}{ Género } & \multirow{3}{*}{$\begin{array}{l}\text { Total } \\
472\end{array}$} \\
\hline & & \multirow{2}{*}{$\begin{array}{r}\text { Hombre } \\
86\end{array}$} & \multirow{2}{*}{$\frac{\text { Mujer }}{386}$} & \\
\hline \multirow{2}{*}{ Educación } & Número & & & \\
\hline & $\%$ & $18.2 \%$ & $81.8 \%$ & $100.0 \%$ \\
\hline \multirow{2}{*}{ Humanidades } & Número & 18 & 50 & 68 \\
\hline & $\%$ & $26.5 \%$ & $73.5 \%$ & $100.0 \%$ \\
\hline \multirow{2}{*}{$\begin{array}{l}\text { Ciencias } \\
\text { Sociales }\end{array}$} & Número & 186 & 362 & 548 \\
\hline & $\%$ & $33.9 \%$ & $66.1 \%$ & $100.0 \%$ \\
\hline \multirow{2}{*}{$\begin{array}{l}\text { Economía y } \\
\text { Empresa }\end{array}$} & Número & 315 & 537 & 852 \\
\hline & $\%$ & $37.0 \%$ & $63.0 \%$ & $100.0 \%$ \\
\hline \multirow{2}{*}{ Derecho } & Número & 178 & 197 & 375 \\
\hline & $\%$ & $47.5 \%$ & $52.5 \%$ & $100.0 \%$ \\
\hline \multirow{2}{*}{ Técnicas } & Número & 566 & 239 & 805 \\
\hline & $\%$ & $70.3 \%$ & $29.7 \%$ & $100.0 \%$ \\
\hline \multirow{2}{*}{ Salud } & Número & 184 & 261 & 445 \\
\hline & $\%$ & $41.3 \%$ & $58.7 \%$ & $100.0 \%$ \\
\hline \multirow{2}{*}{ Ciencias } & Número & 160 & 262 & 422 \\
\hline & $\%$ & $37.9 \%$ & $62.1 \%$ & $100.0 \%$ \\
\hline \multirow{2}{*}{ Total } & Número & 1693 & 2294 & 3987 \\
\hline & $\%$ & $42.5 \%$ & $57.5 \%$ & $100.0 \%$ \\
\hline
\end{tabular}

Fuente: datos PROFLEX.

Tabla 16. Calificaciones y duración de la carrera

\begin{tabular}{|l|c|c|}
\hline \multicolumn{1}{|c|}{ Calificaciones } & Hombre & Mujer \\
\hline \hline Calificación promedio preparatoria $^{*}$ & 3.1 & 3.3 \\
\hline Calificación promedio universidad $^{*}$ & 3.1 & 3.3 \\
\hline \hline Duración promedio carrera (años) & 4.8 & 4.5 \\
\hline
\end{tabular}

*Escala: $1=6-6.9 ; 2=7-7.9 ; 3=8-8.9 ; 4=9-10$. Fuente datos PROFLEX. 
Los dos sectores muestran datos muy similares. Destaca que la asistencia a clases es un factor de alta importancia en ambos sectores, lo cual apunta hacia formas tradicionales de enseñanza. En cambio, las prácticas en empresas o los exámenes de opción múltiple son poco importantes. Las universidades privadas asignan un poco más de importancia a los trabajos escritos o al trabajo en equipo, pero eso no parece explicar las diferentes dinámicas en el marcado de trabajo. Estos datos confirman hallazgos de otros estudios que postulan que los sectores privado y público constituyen dos mundos distintos, pero que la diferenciación no se basa en aspectos académicos, sino en factores sociales (De Garay, 2002). Revisaremos entonces a que factores sociales se pueden deber las diferencias.

\section{Diferencias por género}

Dentro de la muestra, las mujeres constituyen el $57.5 \%$ y los hombres el $42.5 \%$. La distribución por áreas de conocimiento evidencia el avance de las mujeres en la mayoría de las carreras, un aumento que se debe a dos factores: primero, hacia el año 2000, la mujer logró rebasar al hombre en el acceso. Segundo, la mujer demuestra un mejor desempeño durante la carrera en cuanto a permanencia y titulación. Con ello, la participación femenina en el egreso rebasó al 50\% en casi todas las áreas, salvo en las Técnicas.
El desigual desempeño por género se evidencia en la calificación promedio en la escuela preparatoria y la universidad. Las mujeres alcanzan mejores promedios (aunque ambos géneros reportan altas calificaciones, lo cual apunta hacia una inflación de calificaciones) y terminan la carrera en menos tiempo. También tienden a interrumpir menos sus estudios: el 10.7\% de los hombres indica haber interrumpido la carrera durante más de cuatro meses consecutivos, contra el $7.2 \%$ de las mujeres. Igualmente, para el $71.5 \%$ de los hombres, el estudio era la actividad principal durante los últimos dos años de la carrera, contra el 78.7\% de las mujeres. Estos porcentajes son muy similares si comparamos el sector privado con el público.

Aunque las mujeres rebasaron a los hombres en el egreso, cabe preguntarse si esto se traduce también en una mayor participación en el mercado laboral. La tabla 17 revela que está trabajando el $90 \%$ de los hombres y el $82 \%$ de las mujeres.

Si bien la tasa de desempleo es más alta entre mujeres, no implica que todas estén buscando trabajo. Si consideramos como desempleados sólo a aquellos que buscaron trabajo en las cuatro semanas antes de la entrevista, la tasa de desempleo abierto baja hasta $6.2 \%$ para hombres y $7.5 \%$ para mujeres. Esto implica que el $10 \%$ de las mujeres con estudios universitarios opta por no trabajar, frente a sólo el 3.5\% de los hombres. El dato para

Tabla 17. Situación laboral

\begin{tabular}{|l|c|c|c|}
\hline \multicolumn{1}{|c|}{ Situación laboral } & Hombre & Mujer & Total \\
\hline Con trabajo & $90.3 \%$ & $82.2 \%$ & $86.0 \%$ \\
\hline Sin trabajo & $9.7 \%$ & $17.8 \%$ & $14.0 \%$ \\
\hline Sin trabajo, pero estoy buscando & $6.2 \%$ & $7.5 \%$ & $6.9 \%$ \\
\hline
\end{tabular}

Fuente: datos PROFLEX. 
las mujeres desempleadas es el más alto dentro de los países participantes en PROFLEX.

La diferencia se puede explicar por la permanencia de ciertas tradiciones: la tasa de desempleo para mujeres se eleva hasta un $32.1 \%$ para aquellas que tienen hijos (frente a un $14.9 \%$ para aquellas que no tienen). Las tasas brutas de desempleo más bajas se dan en el caso de parejas sin hijos: 7.3\% para hombres, $10.1 \%$ para mujeres. Para parejas con hijos, la relación cambia hacia $6 \%$ para hombres, pero $28.8 \%$ para mujeres. En el caso mexicano, el $64.2 \%$ de los egresados reporta no tener hijos, pero en el caso español es el 89.6\% (Mora et al., 2010). Así, la participación de hombres y mujeres en el empleo está mediada no sólo por el mercado, sino por razones personales y familiares.

Al preguntar por el salario mensual bruto, también se evidencian diferencias importantes. En general, las mujeres reciben $26 \%$ menos en remuneraciones, lo cual confirmaría la persistencia de una fuerte discriminación en el mercado laboral.

Sin embargo, si analizamos los datos por áreas de conocimiento (tabla 18) resaltan contrastes significativos: en Educación, Humanidades y Derecho las mujeres ganan ya en promedio más que los hombres. En cambio, las áreas que desfavorecen a las mujeres son las Sociales y las Ciencias, seguidas por Economía y Empresa, y Salud. Llama la atención que las Técnicas discriminan a la mujer en cuanto al acceso, pero mucho menos en el salario.

Destaca que las mujeres en algunas áreas pueden ganar menos que sus colegas varones, pero más que los hombres en otras áreas. Por ejemplo, una mujer que estudió Derecho tiende a ganar más que un hombre que estudió Ciencias.

La diferencia en ingresos se puede explicar, aunque sea parcialmente, por las horas laboradas. Las mujeres suelen trabajar, en promedio, cinco horas menos a la semana (tabla 19).

Una segunda explicación es el tipo de puesto: el $17 \%$ de los hombres llega a ocupar un puesto directivo, frente al 11\% de las mujeres. En cambio, las mujeres ocupan más frecuentemente puestos de empleada de oficina, con ingresos más bajos (tabla 20).

En cuanto a la satisfacción con el empleo, hombres y mujeres reportan similitudes: el 1.7\% de los hombres está muy insatisfecho, frente al 1.2\% de las mujeres. En el otro extremo tenemos al $42.1 \%$ de la mujeres muy satisfechas con su empleo y al $40.5 \%$ de los hombres.

Aunque las brechas entre géneros se han ido cerrando, todavía permanecen diferencias entre hombres y mujeres en el mercado laboral. Ahora bien, si consideramos que las mujeres suelen terminar sus estudios en menor tiempo y con mejores calificaciones, las diferencias aparentemente no se deben al desempeño mostrado en la universidad. Un factor adicional puede ser el origen social y económico.

\section{El origen familiar}

De acuerdo con Pascarella y Terenzini (2005), el capital educativo familiar de un estudiante puede jugar un papel importante para su desempeño, tanto en la universidad como en el mercado laboral.

Un primer dato de la encuesta PROFLEX parece confirmar esta conjetura. Si comparamos el nivel de escolaridad del padre del egresado con los ingresos reportados por el mismo, resulta una relación directa: entre más alta la escolaridad del padre, mayor el ingreso. Es particularmente notable la diferencia entre padres con secundaria o menos, y aquellos con preparatoria o más (tabla 21).

Ahora bien, surge la pregunta de si esta relación entre origen y destino está mediada por elecciones educativas. Si comparamos los sectores público y privado en cuanto a la escolaridad de los padres, resulta que hay grandes diferencias.

Las tablas 22 y 23 indican que la universidad privada atiende estudiantes con mucho más capital educativo, expresado en la escolaridad de los padres. Como señala De Garay (2002), el sector 
Tabla 18. ¿Cuál es aproximadamente tu sueldo mensual bruto? (pesos mexicanos de 2008).

Por género y área de conocimiento

\begin{tabular}{|c|c|c|c|c|}
\hline Área & Género & $\begin{array}{l}\text { Salario } \\
\text { (media) }\end{array}$ & Número & $\begin{array}{c}\text { Diferencia } \\
\text { mujeres-hombres } \\
\text { (\%) }\end{array}$ \\
\hline \multirow{3}{*}{ Educación } & Hombre & 5655 & 18 & \multirow{3}{*}{$13.86 \%$} \\
\hline & Mujer & 6438 & 59 & \\
\hline & Total & 6255 & 77 & \\
\hline \multirow{3}{*}{ Humanidades } & Hombre & 5446 & 69 & \multirow{3}{*}{$82.80 \%$} \\
\hline & Mujer & 9956 & 147 & \\
\hline & Total & 8515 & 216 & \\
\hline \multirow{3}{*}{ Ciencias sociales } & Hombre & 10467 & 148 & \multirow{3}{*}{$-43.55 \%$} \\
\hline & Mujer & 5909 & 305 & \\
\hline & Total & 7398 & 453 & \\
\hline \multirow{3}{*}{$\begin{array}{l}\text { Economia y } \\
\text { Empresa }\end{array}$} & Hombre & 11026 & 290 & \multirow{3}{*}{$-32.73 \%$} \\
\hline & Mujer & 7417 & 447 & \\
\hline & Total & 8837 & 737 & \\
\hline \multirow{3}{*}{ Derecho } & Hombre & 9370 & 154 & \multirow{3}{*}{$2.17 \%$} \\
\hline & Mujer & 9574 & 159 & \\
\hline & Total & 9473 & 313 & \\
\hline \multirow{3}{*}{ Técnicas } & Hombre & 9873 & 719 & \multirow{3}{*}{$-26.31 \%$} \\
\hline & Mujer & 7276 & 280 & \\
\hline & Total & 9145 & 999 & \\
\hline \multirow{3}{*}{ Salud } & Hombre & 6845 & 174 & \multirow{3}{*}{$-28.91 \%$} \\
\hline & Mujer & 4867 & 243 & \\
\hline & Total & 5692 & 417 & \\
\hline \multirow{3}{*}{ Ciencias } & Hombre & 7287 & 71 & \multirow{3}{*}{$-37.06 \%$} \\
\hline & Mujer & 4587 & 104 & \\
\hline & Total & 5682 & 175 & \\
\hline \multirow{3}{*}{ Total } & Hombre & 9418 & 1643 & \multirow{3}{*}{$-25.85 \%$} \\
\hline & Mujer & 6984 & 1744 & \\
\hline & Total & 8165 & 3387 & \\
\hline
\end{tabular}


Tabla 19. Promedio de horas que trabaja por semana

\begin{tabular}{|l|c|c|}
\hline \multicolumn{1}{|c|}{ Género } & Media & Número \\
\hline Hombre & 39.05 & 1672 \\
\hline Mujer & 33.63 & 1779 \\
\hline Total & 36.25 & 3451 \\
\hline
\end{tabular}

Fuente: datos PROFLEX.

Tabla 20. ¿Cuál es tu puesto y cuál es aproximadamente tu sueldo mensual bruto? (pesos mexicanos de 2008)

\begin{tabular}{|c|c|c|c|c|c|}
\hline \multirow{3}{*}{\begin{tabular}{|l|} 
Puesto \\
Directivos
\end{tabular}} & \multicolumn{2}{|c|}{$\begin{array}{c}\text { Sueldo } \\
\text { promedio }\end{array}$} & \multirow{2}{*}{\begin{tabular}{|c|} 
Hombre \\
282 \\
\end{tabular}} & \multirow{2}{*}{\begin{tabular}{c|} 
Mujer \\
194 \\
\end{tabular}} & \multirow{2}{*}{$\begin{array}{l}\text { Total } \\
476\end{array}$} \\
\hline & $\$ 19,327.00$ & Número & & & \\
\hline & & $\%$ & $17.40 \%$ & $11.20 \%$ & $14.20 \%$ \\
\hline \multirow[t]{2}{*}{ Profesional científico } & \multirow[t]{2}{*}{$\$ 6,573.00$} & Número & 769 & 829 & 1598 \\
\hline & & $\%$ & $47.60 \%$ & $48.10 \%$ & $47.80 \%$ \\
\hline \multirow[t]{2}{*}{ Técnico de nivel medio } & \multirow[t]{2}{*}{$\$ 9,479.00$} & Número & 220 & 251 & 471 \\
\hline & & $\%$ & $13.60 \%$ & $14.60 \%$ & $14.10 \%$ \\
\hline \multirow[t]{2}{*}{ Empleado de oficina } & \multirow[t]{2}{*}{$\$ 9,553.00$} & Número & 217 & 364 & 581 \\
\hline & & $\%$ & $13.40 \%$ & $21.10 \%$ & $17.40 \%$ \\
\hline \multirow[t]{2}{*}{ Otros } & \multirow[t]{2}{*}{$\$ 4,706.00$} & Número & 129 & 87 & 216 \\
\hline & & $\%$ & $8.00 \%$ & $5.00 \%$ & $6.50 \%$ \\
\hline \multirow[t]{2}{*}{ Total } & \multirow[t]{2}{*}{$\$ 9,215.00$} & Número & 1617 & 1725 & 3342 \\
\hline & & $\%$ & $100.00 \%$ & $100.00 \%$ & $100.00 \%$ \\
\hline
\end{tabular}

Fuente: datos PROFLEX. 
Tabla 21. Escolaridad del padre e ingreso mensual del egresado (pesos mexicanos de 2008)

\begin{tabular}{|l|c|c|}
\hline Escolaridad padre & Número & $\begin{array}{c}\text { Salario } \\
\text { mensual } \\
\text { promedio }\end{array}$ \\
\hline Sin estudios & 297 & 1808 \\
\hline Primaria & 643 & 7799 \\
\hline Secundaria & 546 & 6882 \\
\hline $\begin{array}{l}\text { Preparatoria o } \\
\text { Técnico }\end{array}$ & 353 & 14415 \\
\hline Licenciatura & 604 & 14333 \\
\hline Posgrado & 144 & 15503 \\
\hline No aplicable & 21 & 9482 \\
\hline Total & 2609 & 9773 \\
\hline
\end{tabular}

Fuente: datos PROFLEX.

Tabla 22. Nivel de estudios del padre y de la madre por sectores (distribución porcentual)

\begin{tabular}{|c|c|c|c|c|}
\hline \multicolumn{1}{|c|}{ Sector } & \multicolumn{2}{|c|}{ Universidad pública } & \multicolumn{2}{c|}{ Universidad privada } \\
\hline Escolaridad & Padre & Madre & \multicolumn{1}{|c|}{ Padre } & Madre \\
\hline Sin estudios & $3.2 \%$ & $5.3 \%$ & $0.7 \%$ & $0.7 \%$ \\
\hline \hline Primaria & $30.1 \%$ & $33.0 \%$ & $6.5 \%$ & $10.0 \%$ \\
\hline \hline Secundaria & $17.0 \%$ & $21.2 \%$ & $8.8 \%$ & $13.7 \%$ \\
\hline $\begin{array}{c}\text { Preparatoria } \\
\text { o Técnico }\end{array}$ & $21.4 \%$ & $22.5 \%$ & $21.1 \%$ & $43.2 \%$ \\
\hline Licenciatura & $22.8 \%$ & $15.5 \%$ & $49.8 \%$ & $26.8 \%$ \\
\hline \hline Posgrado & $5.5 \%$ & $2.6 \%$ & $13.1 \%$ & $5.5 \%$ \\
\hline \hline Total & $100 \%$ & $100 \%$ & $100 \%$ & $100 \%$ \\
\hline \hline
\end{tabular}

Fuente: datos PROFLEX. 
Tabla 23. Nivel promedio de estudios de los padres

\begin{tabular}{|l|l|r|r|}
\hline \multicolumn{2}{|c|}{ ¿Cuál es / era el nivel de estudios de tus padres? } \\
\cline { 4 - 5 } & \multicolumn{1}{|c|}{ Padre } & \multicolumn{1}{c|}{ Madre } \\
\hline \hline \multicolumn{1}{|c|}{} & \multicolumn{1}{|c|}{ Media } & \multicolumn{1}{c|}{ Media } \\
\hline Género & & 3.30 & 3.00 \\
\hline Hombre & Universidad pública & 4.48 & 4.01 \\
\hline & Universidad privada & 3.78 & 3.41 \\
\hline \hline & Total & 3.47 & 3.14 \\
\hline \hline Mujer & Universidad pública & 4.55 & 4.06 \\
\hline \hline & Universidad privada & 3.88 & 3.49 \\
\hline \hline & Total & 3.40 & 3.08 \\
\hline Total & Universidad pública & 4.52 & 4.04 \\
\hline \hline & Universidad privada & 3.84 & 3.45 \\
\hline \hline & Total & &
\end{tabular}

Fuente: datos PROFLEX.

privado de "élite" atiende mayoritariamente a los "herederos" (aquellos estudiantes cuyos padres ya cuentan con estudios superiores), mientras un sector importante de estudiantes en la universidad pública sigue siendo "pionero" (los primeros en su familia que acceden a la educación superior). La diferencia es grande: el nivel de escolaridad de la madre es más alto en el sector privado, que el nivel de escolaridad del padre en el sector público.

Un factor común para todos los sistemas de educación superior es que los herederos tienen más probabilidad de acceder a la educación superior que los pioneros (Pascarella y Terenzini, 2005). Lo distintivo del caso mexicano es que cada grupo tiende a atender un sector distinto de educación superior, y que esta elección o selección se traduce en fuertes diferencias en ingresos y puestos en el mercado laboral. Otro distintivo es que esta segmentación no se basa en criterios académicos, sino sociales. Es decir, cuando preguntamos por el promedio de calificación en la escuela preparatoria, los estudiantes de ambos sectores reportan el mismo dato. Además, en términos académicos, ambos sectores se caracterizan hoy en día por un proceso de admisión altamente selectivo, admitiendo a menos de la mitad de los aspirantes a partir del promedio de calificaciones en la escuela preparatoria y de un examen estandarizado de conocimientos.

En el caso mexicano, esta selección se da a partir de niveles anteriores de educación. En el nivel secundario, los estudiantes de las instituciones privadas demuestran resultados ligeramente mejores en los exámenes nacionales de conocimiento, pero estas diferencias al parecer se deben parcialmente al origen social (Mexicanos Primero, 2010). Al respecto, una omisión en la encuesta PROFLEX fue no preguntar si los egresados asistieron a una escuela pública o privada previamente a la educación superior. 
Aun así, al analizar el tránsito de la universidad hacia el mercado de trabajo, destaca que el tipo de institución, pública o privada, resulta ser el factor principal de distinción. Por la peculiar organización del sistema, en muchas ocasiones origen es destino, porque el tipo de institución juega un papel importante.

\section{Conclusiones}

Los datos del seguimiento de egresados de PROFLEX indican que hay problemas de desempleo, pero que la inserción exitosa (medida en términos de empleo y de sueldo) es el resultado de una complicada interacción entre el desarrollo de la economía, el área de conocimiento, el tipo de institución (privada-pública), el género y el pasado familiar.

Contrario a otros países (Machin y McNally, 2007), el mercado de trabajo mexicano demuestra algunas señales de sobreoferta de graduados: la tasa de desempleo — neta o bruta- es más elevada que en países comparables, mientras que los salarios son los más bajos en el conjunto de PROFLEX, incluso después de ajustar por la Paridad del Poder Adquisitivo.

Esta situación se presenta en un contexto donde hay, comparativamente, una baja cobertura. Paradójicamente, la ganancia salarial que brida la educación superior, en comparación con el PIB per capita, se ubica entre los lugares más altos, lo cual indicaría que el mercado no está saturado (Llamas Huitrón, 2003). Es decir, sigue habiendo ganancias adicionales a partir de estudios universitarios, lo cual implica que conviene cursar estudios universitarios.

Al mismo tiempo, no hay señales de que exista un desplazamiento de los egresados hacia sectores de la economía que no requerirían estudios universitarios, como ocurre en otros países con una cobertura más amplia. Más bien, apuntan hacia una situación en que el mercado profesional sí genera empleos, pero con salarios muy diferenciados, y de manera insuficiente en ciertas áreas del conocimiento. Parece haber una sobreoferta (o más bien, una escasez en la demanda) en áreas como las Ciencias y las Humanidades, pero no en carreras tradicionales como Derecho, contrario a lo que proclaman varios documentos oficiales.

Hay notables diferencias entre egresados de universidades públicas y privadas, incluso dentro de carreras prácticamente idénticas. Además, los egresados señalan la creciente necesidad de contar con un posgrado, incluso para puestos con bajos ingresos.

Los problemas en el mercado no parecen deberse a una falta de preparación en términos de competencias. La creciente exigencia de posgrados más bien apunta a una fuerte competencia por ingresar a los puestos dentro de un mercado fuertemente estratificado. El acceso a diferentes estratos y puestos depende todavía del género, pero en este aspecto las brechas se están cerrando paulatinamente. Sin embargo, las principales brechas se relacionan con el tipo de institución. A su vez, el acceso a cada tipo de institución depende del capital educativo y económico de cada familia. El sistema de educación superior se encuentra claramente segmentado, a diferencia de otros países, y refleja la polarización social y cultural actual.

De este modo, el problema central para el caso mexicano no parece ser el acceso a la educación superior o la formación que las universidades brindan. Más bien, el problema está en la fuerte desigualdad social y económica dentro del mercado de profesionistas del país, combinado con un sistema educativo estratificado. En este contexto, la educación superior funciona como instancia que ratifica las diferencias, en vez de mitigarlas. Las diferencias se basan en factores sociales, no en diferentes desempeños académicos.

Considerando estos factores, destaca que las políticas públicas de las últimas dos décadas han contribuido poco a mitigar las desigualdades. Acciones como la creación de nuevas instituciones públicas, 
las múltiples revisiones curriculares, el freno al ingreso a ciertas carreras, los procesos de evaluación y acreditación, o las mejoras en la preparación de profesores en el sector público, han cambiado a lo que se consideran como los indicadores de calidad. Sin embargo, no han transformado las perspectivas de empleo para los egresados.

Un problema crucial en el caso mexicano es que el mercado de trabajo está fuertemente segmentado y que las contrataciones se orientan por el tipo

\section{Referencias}

Cabrera, A., W. de Vries y S. Anderson (2008), "Job satisfaction among mexican alumni: a case of incongruence between hunch-based policies and labor market demands", en Higher Education, núm. 56, pp. 699-722.

Castells, M. (2004), La era de la información: economía, sociedad y cultura, Madrid, Alianza Editores.

Comisión Económica para América Latina y el

Caribe/Organización de las Naciones Unidas para la Educación, la Ciencia y la Cultura (CEPAL/ UNESCO) (1992), Educación y conocimiento: eje de transformación productiva con equidad, Santiago de Chile, CEPAL/UNESCO.

De Garay, A. (2002), "Un sistema de educación superior, dos realidades distintas: la universidad pública y la universidad privada", en Revista de Educación Superior, vol. XXXI, núm. 122, pp. 69-77.

De Vries, W. y G. Álvarez (2005), "Acerca de las políticas, la política y otras complicaciones en la educación superior mexicana", en Revista de Educación Superior, vol. XXXIV (2), núm. 134, pp. 81-106.

Díaz-Barriga, A. (2006), "El enfoque de competencias en la educación. ¿Una alternativa o un disfraz de cambio?", en Perfiles Educativos, vol. XXVII, núm. 111, pp. 7-36.

El Economista (2009), "Desempleo, en su mayor nivel desde 2004: INEGI", en El Economista, 21 de de institución, más que por el desempeño académico. El problema para las políticas educativas es que han podido cambiar parcialmente a las instituciones educativas, a partir de una idea de que los cambios en los insumos y procesos mejorarán el desempeño en el mercado laboral. Pero al parecer, han tenido pocos efectos en el mercado de trabajo. En la relación entre la educación superior y el empleo, quizá el factor más problemático es que el mercado de trabajo sigue siendo muy tradicional.

enero, <http://eleconomista.com.mx/notas-online/ negocios/2009/01/21/desempleo-su-mayor-nivel2004-inegi> [consulta: 18 de febrero 2009].

Flores-Crespo, P. y C. Muñoz Izquierdo (2009), "Crisis y desempleo: ¿podrán hacer algo las universidades?”, en Campus Milenio, 19 de febrero, <http://www. campusmilenio.com.mx/309/ensayos/index.php> [consulta: 20 de febrero 2009].

Llamas Huitrón, I. (2003), "Equidad en la asignación de recursos en educación", en A. Morduchowicz, Equidad y financiamiento de la educación en América Latina, Buenos Aires, IIPE-UNESCO, pp. 59-88.

La Jornada, (2009), "SEP: 45\% de profesionistas, en áreas ajenas a su especialidad", nota de Emir Olivares, 6 de febrero, <http://www.jornada.unam. $\mathrm{mx} / 2009 / 02 / 06 /$ index.php?section=sociedad $\&$ arti cle $=035 \mathrm{n} 1 \mathrm{soc}>$ [consulta: 6 de febrero 2009].

Machin, S. y S. McNally (2007), Tertiary education systems and the labour market. A paper commissioned by the Education and Training Policy Division, OECD, for the Thematic Review of Tertiary Education, París, OECD.

Márquez, A. (2008), "Jóvenes mexicanos: su horizonte de posibilidades de participación en la educación y el trabajo", en M. L. Suárez y J. A. Pérez (coords.), Jóvenes universitarios en Latinoamérica, hoy, México, Universidad Nacional Autónoma de México/ Miguel Ángel Porrúa. 
Mexicanos Primero (2010), Brechas. Estado de la Educaciónen México 2010, México, Mexicanos Primero Visión 2030, <http://www.mexicanosprimero.org/ images/stories/Reporte_Mexicanos_Primero_-Brechas_2010.pdf $>$ [consulta: 15 de enero 2011].

Mora, J. G., J. M. Carot y A. Conchada (2010), Informe resumen del proyecto PROFLEX en América Latina. Comparativa con el proyecto REFLEX en Europa, Valencia, Universidad Politécnica de Valencia/ CEGES.

Muñoz, C. (1996), Origen y consecuencias de las desigualdades educativas. Investigaciones realizadas en América Latina sobre el problema, México, Fondo de Cultura Económica.

Pascarella, E. T. y P.T. Terenzini (2005), How college affects students: a third decade of research, San Francisco C.A., Jossey-Bass.
Perrenoud, P. (1999), Dix nouvelles competénces pour enseigner. Invitation au voyage, París, ESF.

Rodríguez, R. (2010) "Acuse de recibo: más sobre cobertura", en Campus Milenio, 4 de noviembre, <http://www.campusmilenio.com.mx/392/opinion/ rrg.html> [consulta 9 de noviembre de 2010].

Rubio, J., (coord.) (2006), La politica educativa y la educación superior en México. 1995-2006: un balance, México, Fondo de Cultura Económica/Secretaria de Educación Pública.

Task Force on Higher Education and Society (2000), Higher education in developing countries. Peril and promise, Washington, D.C., Banco Mundial.

United Nations Development Programme (UNDP) (2010), International human development indicators, $<$ http://hdr.undp.org > [consulta: 02 de febrero de 2011].

\section{Cómo citar este artículo:}

De Vries, Wietse y Yadira Navarro (2011), “¿Profesionistas del futuro o futuros taxistas? Los egresados universitarios y el mercado laboral en México”, en Revista Iberoamericana de Educación Superior (RIES), México, ISSUE-UNAM/Universia, vol. II, núm. 4, pp. 3-27, http://ries.universia.net/index.php/ries/article/view/71 [consulta: fecha de última consulta]. 